\title{
Tecnologias Digitais e o Ensino de Estatística: conhecendo a Estatística a partir de um recurso educacional digital
}

\author{
${ }^{1}$ Karen Emanuelle C. Fernandes, Glejane B. Sousa, Francisca Kelly D. Silva, Gleison S. \\ Lima, Darlene Alves Leitão, Danilo do Carmo de Souza, Juscileide Braga de Castro. \\ ${ }^{1}$ Faculdade de Educação - Universidade Federal do Ceará (UFC) - Fortaleza - CE- Brasil \\ $\{$ karenemanuelle,glejane 4 \} @gmail.com,kellydamasceno.ufc@hotmail.com, \{gslima \\ 02, darlenealvesleitao, danilocarmo1992\} @gmail.com, juscileide@virtual.ufc.br
}

\begin{abstract}
This article presents the development and analysis of a digital resource created in Microsoft Excel to stimulate statistical thinking. The present work is based on the convergence of the prescriptions of legal documents such as BNCC and PCN for Elementary School. It was found that the technologies can contribute with the teaching of Statistics, with the perspective in the exploration of the data and stimulus of the critical spirit. It was verified in the present work that the applicability of the resource is accessible to teachers with less affinity with the technology, in the same way that it overcomes the limitations found in the use of Microsoft Excel for the teaching of graph analysis.
\end{abstract}

Resumo. Este artigo apresenta o desenvolvimento e a análise de um recurso digital criado no Microsoft Excel para estimular o pensamento estatístico. $O$ presente trabalho fundamenta-se na convergência das prescrições de documentos legais como a BNCC e os PCN para o Ensino Fundamental. Verificou-se que as tecnologias podem contribuir com o ensino de Estatística, com a perspectiva na exploração dos dados e estímulo do espírito crítico. Constatou-se no presente trabalho que a aplicabilidade do recurso é acessivel a professores com menos afinidade com a tecnologia, do mesmo modo que supera as limitações encontradas na utilização do Microsoft Excel para o ensino de análise de gráficos.

\section{Introdução}

A Matemática está presente em diversas situações de nosso cotidiano, porém muitas vezes os conhecimentos adquiridos na escola não se transpõem para a vida diária. É nessa perspectiva que documentos recentes como a Base Nacional Comum Curricular (BNCC) e pesquisadores enfatizam que o ensino da Estatística se mostra significativo e necessário, pois pode contribuir para uma melhor compreensão da realidade e para o desenvolvimento de uma atitude crítica às demandas da sociedade [Cazorla et al 2017; Brasil 2017].

Apesar disso, pesquisas como as realizadas pelo Indicador Nacional de Alfabetização Funcional (INAF) têm revelado que cerca de $27 \%$ da população brasileira pode ser considerada analfabeta funcional, pois não conseguem interpretar informações presentes em gráficos e tabelas; e apenas $8 \%$ pode ser considerada alfabetizada, isto é, proficientes [Inaf 2016]. Estes dados são preocupantes, pois mostram que a escola não está oportunizando aos estudantes o desenvolvimento de competências e habilidades relacionadas com a Estatística.

Considerando estas dificuldades, pesquisas [Castro 2012; Castro e Castro- Filho 2012; 2015] têm sido realizadas no intuito de contribuir com a aprendizagem da Estatística por meio da exploração do potencial das tecnologias digitais. Assim, os recursos tecnológicos podem minimizar os esforços na construção de gráficos, priorizando as habilidades mais 
relevantes de interpretação e análise de gráficos em situações reais [Castro 2012]. Nessa perspectiva, a tecnologia tem o potencial de favorecer a representação de informações com mais agilidade; simular diferentes situações; trabalhar com contextos significativos e ainda, ajudar a tratar a informação de todo um processo investigativo [Castro 2012; Cazorla e Utsumi 2010].

Sendo assim, diante das questões até aqui discutidas, este excerto tem como objetivo apresentar o Recurso Educacional Digital (RED): Um herói para Matelândia, desenvolvido para o trabalho com Estatística nas escolas. Destarte, essa pesquisa organiza-se da seguinte forma: a introdução, já descrita, o contexto e as ferramentas tecnológicas utilizadas para a elaboração do referido recurso, a análise e por fim, as considerações finais.

\section{Contexto e Desenvolvimento}

O RED Um herói para Matelândia é fruto de uma das atividades vivenciadas na disciplina de Ensino de Matemática do Curso de Pedagogia da Faculdade de Educação (FACED) da Universidade Federal do Ceará, durante o semestre 2018.1.

Para atender ao objetivo definido, exploraram-se softwares como: Scratch $^{1}$, ToonDoo ${ }^{2}$ e Microsoft Office Excel $^{3}$, a fim de verificar e aplicar suas funcionalidades para criação do RED. Ademais, um dos critérios para o desenvolvimento dos elementos pedagógicos foi oportunizar ao usuário a coleta de dados, o registro gráfico e tabular. O RED tem como público alvo estudantes do $3^{\circ}$ ano do Ensino Fundamental, uma vez que atende ao campo de atuação dos proponentes. Contudo, salientamos que a aplicação do recurso pode adequar-se a outros níveis escolares.

\section{Apresentação do RED: Um herói para Matelândia}

Este RED apresenta uma narrativa de heróis conhecidos das histórias em quadrinhos (Homem de Ferro, Homem Aranha, Viúva Negra, Thor e Mulher Maravilha) que se candidatam para concorrer a super-herói de Matelândia, cidade fictícia (Figura 1). Como o enredo da narrativa apresentou contexto de histórias em quadrinhos, utilizou-se o ToonDoo para desenvolvê-la, uma vez que é um editor de histórias em quadrinho online e parcialmente gratuito.

A Figura 1 apresenta a narrativa desenvolvida para o RED Um herói para Matelândia.

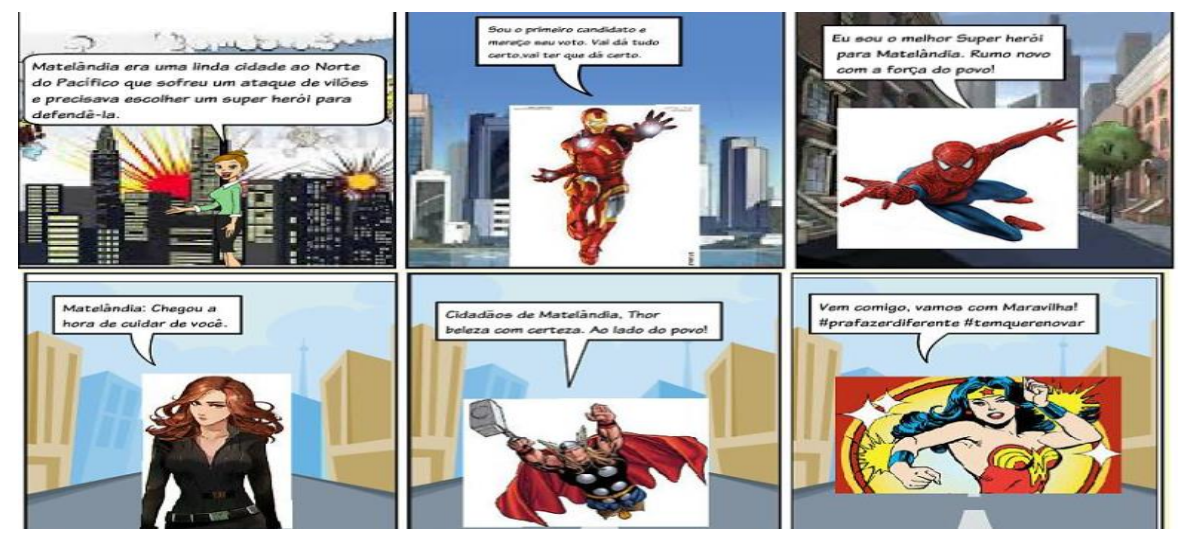

\footnotetext{
${ }^{1}$ Disponível em: https://scratch.mit.edu/

2 Disponível em: http://www.toondoo.com/

${ }^{3} \mathrm{O}$ Microsoft Office Excel é um editor de planilhas produzido pela Microsoft para computadores que utilizam o sistema operacional Windows.
} 
VII Congresso Brasileiro de Informática na Educação (CBIE 2018)

Anais dos Workshops do VII Congresso Brasileiro de Informática na Educação (WCBIE 2018)

\section{Figura 1. Narrativa do RED}

Considerou-se necessária a criação da narrativa com personagens do universo infantil de modo a garantir a imersão da criança e, assim, contribuir com sua aprendizagem. A partir deste RED, o usuário pode iniciar um processo investigativo envolvendo o planejamento, a coleta, a organização dos dados e a construção de gráfico de barras e tabela. Cazorla e Utsumi (2010) destacam que as ferramentas tecnológicas colaboram para um ambiente diversificado e propício a atuação efetiva do estudante. Para Castro e Castro-Filho (2015) a participação em um processo investigativo é importante para a compreensão de conceitos estatísticos e do pensamento estatístico ${ }^{4}$.

A utilização de técnicas avançadas de Excel permitiu programar as células para mudarem de cor à medida que eram clicadas, registrando com facilidade os votos (Figura 2).

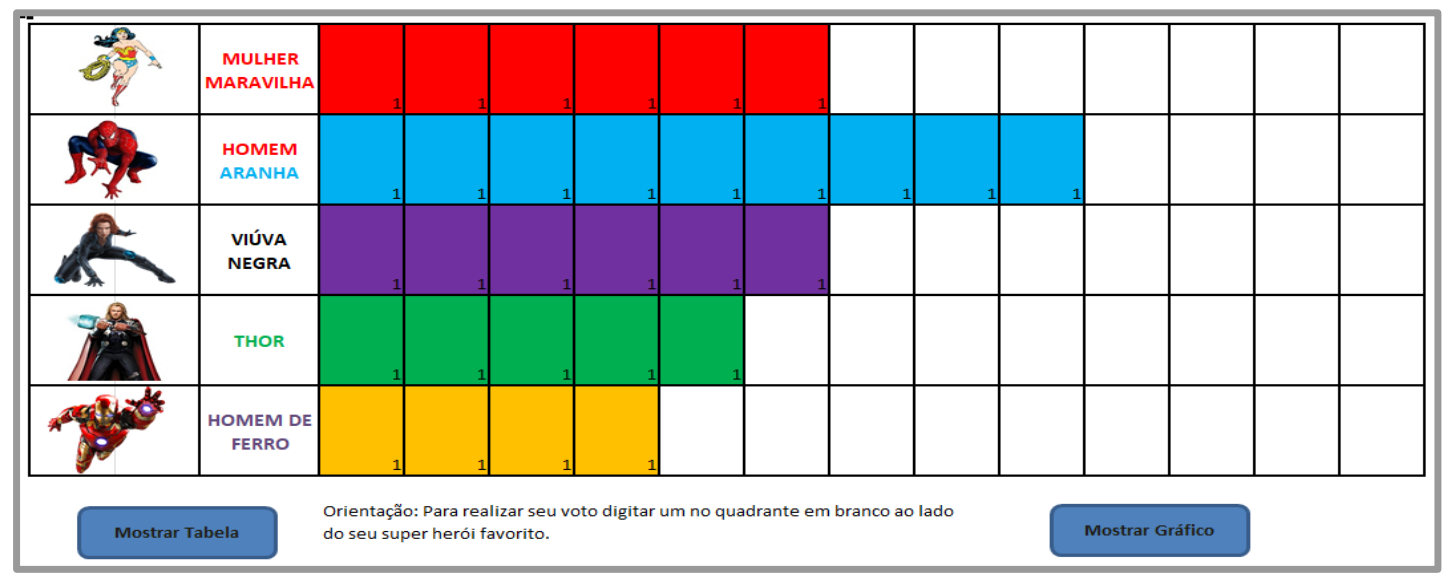

Figura 2. Gráfico de barras

Desta forma, destaca-se como diferencial deste RED a possibilidade de coletar dados com mais facilidade e, também, verificar o gráfico de barras sendo construído à medida que os dados são coletados. Ao finalizar a coleta de dados, o usuário tem a opção de visualizar, nas telas seguintes, o gráfico e a tabela que foram formadas a partir da pesquisa realizada por eles. Em seguida, o usuário deverá fazer a análise dos dados e responder qual o herói vencedor. Nesse momento, o professor pode mediar à atividade questionando as crianças sobre informações presentes nas representações. Por fim, promover o senso crítico a partir de debates, arguições e instigar inferências e discussões a partir dos achados dos estudantes [Cazorla e Utsumi 2010; Brasil 2017].

No tocante a disponibilização e acesso, o RED pode ser usado offline, em qualquer dispositivo que compatível com planilhas eletrônicas, inclusive smartphones, o que possibilita a exploração da mobilidade. Ademais, não é preciso ter conhecimento de Excel, uma vez que o RED já está programado.

A fim de verificar a funcionalidade do RED foi realizada uma validação junto aos estudantes da disciplina de Ensino de Matemática. Durante a utilização do RED verificou-se a participação e o envolvimento dos discentes. Outro fator que se pode destacar é a interdisciplinaridade que o recurso pode promover, por meio dele poderá ser abordado

\footnotetext{
4 “[...] o pensamento estatístico envolve o ato de pensar e fazer predições sobre o processo investigativo, inferindo os resultados a partir das mudanças no processo, desde a definição da amostra até a representação dos resultados" [Castro e Castro-Filho 2015, p. 873].
} 
qualquer tipo de pesquisa, além de deixar a aula mais dinâmica e participativa.

Castro (2012) explica que o Excel não é um software criado para fins educacionais e que, por isso, não contribui com a reflexão sobre a construção de gráficos, uma vez que esta construção acontece de forma automática. Contudo, este RED buscou superar essa limitação ao proporcionar a construção manual e de maneira simples, na qual o aluno verifica essa percepção de forma didática e acessível. A seguir as considerações finais serão dispostas.

\section{Considerações finais}

Este artigo teve como objetivo apresentar um RED desenvolvido para o Ensino de Matemática e que contempla o conteúdo de estatística, como proposta de atividade para alunos do $3^{\circ}$ ano do Ensino Fundamental. Constatou-se que a utilização de recursos tecnológicos vinculados aos conteúdos curriculares possibilita um aprendizado com qualidade e com maior significação, pois ao incentivar o uso dessas tecnologias o aluno fica motivado a participar do processo de aprendizagem de forma lúdica e criativa.

Cabe frisar as contribuições formativas da elaboração do material aqui descrito, já que os proponentes precisaram investigar estratégias e pesquisas para fundamentar as atividades do recurso. Com isso, reforçamos a importância de aliar o conteúdo de Estatística, que muitas vezes é aplicado de maneira bem superficial, mesmo fazendo parte das propostas presentes na BNCC, aos recursos tecnológicos. Em pesquisas futuras espera-se utilizar o RED em uma sequência didática no contexto escolar e posteriormente sua disponibilização de acesso.

\section{Referências}

Brasil, Ministério da Educação (2017) "Base Nacional Comum Curricular". Educação é a base. Brasília: MEC.

Castro, J. B. (2012) "O uso de objetos de aprendizagem para a construção e compreensão de gráficos estatísticos". Fortaleza: UFC, 2012. 215 p. Dissertação (Mestrado) - Programa de Pós Graduação em Educação Brasileira, UFC, Fortaleza.

Castro, J. B.; Castro-Filho, J. A. (2015) "Desenvolvimento do Pensamento Estatístico com suporte Computacional”. Educação Matemática Pesquisa (online), v. 17, p.870-896.

Castro, J. B.; Castro-Filho, J. A. (2012) 'Projeto Um Mundo de Informações: Integração de Tecnologias Digitais ao Currículo Escolar'. In: Congresso Brasileiro de Informática na Educação, 1., 2012, Rio de Janeiro. Anais... Rio de Janeiro: SBC.

Cazorla, I. et al. (2017) "Estatística para os anos iniciais". São Paulo: Sociedade Brasileira de Educação Matemática.

Cazorla, I. M.; Utsumi, M. C. (2010) "Reflexões sobre o ensino de Estatística na Educação Básica". In: CAZORLA, Irene; SANTANA, Eurivalda. Do tratamento da informação ao letramento estatístico. Itabuna: Via Litterarum, p. 9-18.

Inaf, (2016) Indicador de Alfabetismo Funcional - INAF: estudo especial sobre alfabetismo e mundo do trabalho. Instituto Paulo Montenegro em parceria com a ONG Ação Educativa. São Paulo. 